Kansas State University Libraries

New Prairie Press

\title{
Exploring multi-year soybean yield trial data in South Dakota environments
}

\author{
Jixiang Wu \\ South Dakota State University, jixiang.wu@sdstate.edu \\ Jianli Qi \\ South Dakota State University, jianli.qi@sdstate.edu \\ Jonathan Kleinjan \\ South Dakota State University, jonathan.kleinjan@sdstate.edu
}

Follow this and additional works at: https://newprairiepress.org/agstatconference

Part of the Agriculture Commons, and the Applied Statistics Commons

\section{(c) $(1) \Theta \Theta$}

This work is licensed under a Creative Commons Attribution-Noncommercial-No Derivative Works 4.0 License.

\section{Recommended Citation}

Wu, Jixiang; Qi, Jianli; and Kleinjan, Jonathan (2017). "Exploring multi-year soybean yield trial data in South Dakota environments," Conference on Applied Statistics in Agriculture. https://doi.org/10.4148/ 2475-7772.1529

This Event is brought to you for free and open access by the Conferences at New Prairie Press. It has been accepted for inclusion in Conference on Applied Statistics in Agriculture by an authorized administrator of New Prairie Press. For more information, please contact cads@k-state.edu. 


\title{
Exploring multi-year soybean yield pattern under eastern South Dakota environments
}

\author{
Jixiang Wu*, Jianli Qi, and Jonathan Kleinjan \\ Agronomy, Horticulture, and Plant Science Department \\ South Dakota State University, Brookings, SD 57007 \\ *: Corresponding author (Jixiang.wu@sdstate.edu)
}

\begin{abstract}
Soybean is one of the major crops in South Dakota. Crop yield trial is a common practice to evaluate yield performance and adaptability of each variety. In this study, we analyzed the 16years of soybean yield trial data under eastern South Dakota environments, which included seven locations, three maturity zones, and over 1000 different varieties to determine factors associated with soybean production. Due to low repeatability of genotypes among trial years, in this study we focused on descriptive statistics, linear regression analysis, and linear mixed model analysis to determine the yield patterns. The results showed that mean and maximum yield increased $56 \%$ and $35 \%$ from 2001 to 2016, respectively. Results also showed that environmental conditions among locations were a major factor impacting soybean yield for each year. The results were consistent among these three types of analyses. This study demonstrated that breeding efforts contributed to soybean yield improvement over years while growing conditions were another significant factor on soybean yield in South Dakota.
\end{abstract}

Keywords: Multi-year yield trial data, soybean production pattern

\section{Introduction}

Soybean is one of the most important crops in the United States and is among top five crops in South Dakota. Improving soybean production depends on a wide range of factors such as variety selection, environmental condition, and field management and has been a long-time research effort at South Dakota State University (SDSU). Multi-environmental soybean yield trial could help determine factors associated with soybean performance. Like many other state universities in USA, SDSU has been conducting soybean yield tests for decades. Exploring multi-year soybean trial data could help reveal soybean yield pattern and thus improve soybean production under South Dakota environments.

Unlike many other crops, soybean production is related to maturity level. Later maturing varieties tend to yield more seed than early ones when grown at the same locations; however, it may also increase the risk of fall freeze damage due to potential early frost, which could occur in September in South Dakota. Therefore, maturity is the first consideration when choosing a variety suited to a geographical region. Varieties of maturity groups (MG) 0,1 , and 2 are suitable to South Dakota, where MG 0 is most early maturity in this region. Therefore, the locations used for soybean annual yield trials in South Dakota represent these three maturity groups (igrow.org). 
Many approaches have been proposed for and applied to multi-environment yield trial data analysis. Genotype-environment (GE) interaction analysis has been commonly conducted (Gray 1982; Kang and Miller 1984). Stability analysis for each genotype has been a major focus in multienvironment crop yield trials (Eberhart and Russell 1966; Fan et al. 2007; Finlay and Wilkinson 1963; Francis and Kannenberg 1978). Lin et al. (Lin et al. 1986) reviewed and examined nine stability. Additive main and multiplicative interaction (AMMI) method (Crossa et al. 1990) has been one of the most commonly used yield stability methods. GGEbiplot, a graphical tool, can be used for multi-environment trial data for yield stability or GE interaction(de Figueiredo et al. 2015; Yan 2001). Linear mixed model approaches have also been applied to analyze multi-environment trial data to explore genotypic effects, environmental effects, and GE interaction effects with its flexibility for unbalanced data structure and/or missing data points (Zhu et al. 1993; de la Vega et al. 2007).

Most analyses for yield stability and GE interaction were focused on multi-location trials within one year or a few years and a huge number of publications can be found. Revisiting historical yield trial datasets could offer more useful information; however, only a few papers have been available regarding historical yield trial data analysis (de la Vega et al. 2007; Lobell et al. 2011; Mackay et al. 2011). A common issue is that historical yield trial datasets are generally highly unbalanced because most varieties are discarded after a few years (Mackay et al. 2011). With such as significant issue associated with historical datasets, the above mentioned methods may not be appropriate to deal with them.

In this study, our objective was to determine potential factors associated with soybean seed production through analyzing 16-year soybean yield trial data under South Dakota environments. We applied different methods including descriptive statistics, linear mixed model approaches, and linear regression methods to analyze the soybean data. The purpose of this study was to provide useful information for improve soybean production under South Dakota environments in the future.

\section{Materials and Methods}

\section{SD soybean yield trials and data source}

Most soybean farm lands are located in eastern South Dakota. There are three major maturity zones for soybean production in South Dakota: MG 0, MG 1, and MG 2. Total seven locations representing these three MGs are currently used for soybean yield trials in this state (Figure 1). Six locations coded as 1, 2, 3, 8, 10, and 19 have been used for many years while one additional location, coded as 20 , has been added to our soybean trial since 2013. These codes had been initially used for these trial locations and thus were used in this study as well. Locations 3 (South Shore) and 19 (Aberdeen) represent MG 0. Location 1 (Brookings), 8 (Bancroft), 20 (Miller) represent MG 1. Locations 3 (Beresford) and 10 (Geddes) represent MG 2. Locations 1, 2, and 3 are on three SDSU research farms while the other locations are on private farm lands. In order to expand the adaptability test, soybean varieties of MGs 0 and 1 were grown in MG 0 zone (locations 3 and 19). Soybean varieties of MGs 0, 1, and 2 were grown in MG 1 zone (locations 1, 8, and 20) 
and soybean varieties of MGs 1 and 2 were grown in MG 2 zone (locations 2 and 10). Each yield trial followed a randomized complete block design with 6-row plot with three replications. Only two middle rows (rows 3 and 4) were harvested to determine seed yield (bu/ac) at 13\% of moisture level for each plot. Interested readers please refer to the website http://igrow.org for the detailed information on soybean yield trial.

Soybean yield trial data were subtracted from SDSU soybean yield trial reports, which are partially available on the website http://igrow.org. The data contained 16 years (2001 to 2016) of yield trials. The variables used in this study include trial year, test location, maturity group of variety, soybean brand, soybean variety, and seed yield. Only individual genotypic means from each environment were used for analysis.

\section{Statistical data analyses}

Due to the highly unbalanced data structures among years, our data analyses included three components. The first component was focused on descriptive statistics like yield distributions across and within years, locations, and maturity groups (Tables 2-4 and Figures 2-7). The second component focused on linear regression of soybean yield (including mean yield and maximum yield each year) on 16 testing years (Figure 8). The similar linear regression analysis was also conducted for each location and for each maturity group (Tables 5 and 6). The third component was to estimate the contribution from environmental conditions for each year with linear mixed model approaches (Patterson and Thompson 1971; Rao 1971; Zhu 1989). The linear mixed model used for the third component included location effect, maturity group effect, variety (or genotypic) effect nested to maturity groups, and random error (Figure 9). Genotype-by-location interaction effects were not included because the data used were not replicated. All data analyses were conducted in the $\mathrm{R}$ environment ( $\mathrm{R}$ Core Team 2017). The $\mathrm{R}$ package minque package (Wu 2014) was used for linear mixed model analysis.

\section{Results}

\section{Entry and brand frequencies across years}

The numbers of entries grown in each location and total entries, varieties, and seed brands for each year are summarized in Table 1. Location 20, which represents a west area in South Dakota has been added to the soybean yield trials since 2013. The plots for location 19 (Aberdeen) in 2001 and 2002, and for location 8 (Bancroft) in 2004 were not harvested due to the weather conditions during the growing seasons (Table 1). There were 71 seed brands over 16 years of yield trails. The minimum brand number was 16 in 2012 and the maximum was 39 in both 2001 and 2002 (Table 1). The most grown brands included Prairie, Kruger, Mustang, Wensman, Nutech, Asgrow, Hefty, and Dairyland (Figure 2). 
There were total 2946 different soybean genotypes grown over 16 years. Among them, there were 574, 1216, and 1156 genotypes with MG 0,1, and 2, respectively. Overall, the total numbers of entries in the trial decreased for each location from 2001 to 2016 and the total entry numbers decreased from 927 in 2001 to 456 in 2016 as well (Table 1). In the same manner, the total variety numbers decreased from 416 in 2001 to 151 in 2016. From years 2001 to 2004, over 30 seed suppliers provided seed for yield trials while from 2005 to 2016 fewer than 30 seed suppliers provided seeds for yield trials (Table 1). There were 2200 total entries grown in location 1 (Brookings) over 16 years while 281 entries grown in location 20 (Miller) during the recent four years (2013-2016) (Table 1 and Figure 3). The numbers of entries grown in the other five locations ranged from 1337 to 1770 (Table 1 and Figure 3). The numbers of seed brands over 16 years ranged from 52 (Miller) and 66 (South Shore) among these seven locations. Over 1000 different varieties were grown in locations 1, 2, 3, 8, and 10 while 939 and 212 different soybean varieties were grown in locations 19 and 20 (Table 1). There were 1993, 4840, and 3671 entries (Figure 4) and 574, 1216, and 1156 different varieties from MG 0, 1, and 2, respectively, belonging to 62, 68 , and 60 of seed brands from these three maturity groups.

\section{Yield distribution for different years}

Yield distributions for 16 years are summarized in Table 2 and Figure 5. Mean yield increased from 42.64 to $66.64 \mathrm{bu} / \mathrm{ac}$ over 16 years, which was $56 \%$ of yield increase compared to the mean yield in 2001. Maximum yield increased from 62.20 to $84.08 \mathrm{bu} / \mathrm{ac}$ over 16 years, which was $35 \%$ of yield increase compared to the maximum yield in 2001. There were three years (2001, 2002, and 2007) with maximum seed yield between 60-70 bu/ac and five years (2004-2006 and 2009-2016) with maximum seed yield above 70bu/ac. The maximum yield reached $84 \mathrm{bu} / \mathrm{ac}$ on in 2016. Except 2003 and 2012, at least over 60\% of entries yielded more than 40 bu/ac. In 2007, 2009, 2010, 2013, 2015, and 2016, over 90\% of entries yield over 40 bu/ac. In 2005, 2009-2011, and 2013-2016, around and above 30\% of entries yielded more than $60 \mathrm{bu} / \mathrm{ac}$. In 2016, there were $5 \%$ of entries yielded more than 80 bu/ac (Figure 5). In both 2003 and 2012, over 10\% of entries yielded less than $20 \mathrm{bu} / \mathrm{ac}$ of soybean seed.

\section{Yield distributions for different locations}

Yield distributions for seven locations across 16 years are presented in Table 3 and Figure 6. Mean yield over 16 years for locations 1, 3, 8, 19, 20 reached 50 bu/ac while less than $45 \mathrm{bu} / \mathrm{ac}$ for locations 2 and 10. The lowest yield over 16 years was $7 \mathrm{bu} / \mathrm{ac}$ at location 3 while the highest yield has reached over $80 \mathrm{bu} / \mathrm{ac}$ for locations 1(Brookings) and 3 (Beresford) and over $70 \mathrm{bu} / \mathrm{ac}$ for other locations except location 2 (South Shore, $69.73 \mathrm{bu} / \mathrm{ac}$ ). There were 15 and eight different genotypes yielded more than $80 \mathrm{bu} / \mathrm{ac}$ in locations 1 and 3, respectively. More than 60\% (67-92\%) of entries yielded over $40 \mathrm{bu} / \mathrm{ac}$ of soybean seed for all locations (Figure 6). For example, in locations $1,3,8$, and 19 , over $80 \%$ of entries yielded more than 40 bu/ac. Over $20 \%$ of entries

yielded more than $60 \mathrm{bu} / \mathrm{ac}$ in locations $1,3,8$, and 19. These results indicated relatively higher mean yield for these four locations. A small portion of entries $(<5 \%)$ yielded less than $20 \mathrm{bu} / \mathrm{ac}$ in 
locations $2,3,8$, and 9 and a slight portion of entries $(<1 \%)$ yielded over $80 \mathrm{bu} / \mathrm{ac}$ in locations 1 and 3 (Figure 4).

\section{Yield distributions for three maturity groups}

Yield distributions for three maturity groups across 16 years are summarized in Table 4 and Figure 7. Mean yield was similar between MGs 1 and 2 (50.35 bu/ac vs $50.52 \mathrm{bu} / \mathrm{ac})$ but was slightly higher than mean yield from MG 0 (47.11 bu/ac) (Table 4). The highest yield from MG 0 was $73.29 \mathrm{bu} / \mathrm{ac}$ while it was $83.24 \mathrm{bu} / \mathrm{ac}$ from MG 1 and $84.08 \mathrm{bu} / \mathrm{ac}$ from MG 2. Twenty-three (23) entries/varieties (16 from MG 1 and 7 from MG 2) yielded more than $80 \mathrm{bu} / \mathrm{ac}$ of soybean seed. More than $70 \%(73 \%, 82 \%$, and $83 \%$ for MG 0, 1, and 2) of entries yielded over $40 \mathrm{bu} / \mathrm{ac}$ of soybean seed for three maturity groups (Figure 7). Fifteen percent, $24 \%$, and $24 \%$ of entries yielded more than $60 \mathrm{bu} / \mathrm{ac}$ for MG 0,1 , and $2 \mathrm{~m}$ respectively. Only A small portion of entries $(1.5 \%, 1.9 \%$, and $2.2 \%$ for MG 0, 1, and 2) yielded less than $20 \mathrm{bu} / \mathrm{ac}$.

\section{Linear regression analysis for mean yield and maximum over year}

Mean yield and maximum yield from each year on these 16 trial years were analyzed using simple linear model. The results are presented on Figure 8. Both mean yield and maximum yield showed strong and positive linear relationship with trial years with slopes of 1.26 and $1.05 \mathrm{bu} / \mathrm{ac}$ and coefficients of determination of 0.45 and 0.41 (Figure 8). The slope estimates suggested the overall annual increases in annual mean yield and maximum yield reached 1.26 and $1.05 \mathrm{bu} / \mathrm{ac}$. The results highly supported the results in Table 2 and Figure 5.

Because location 20 was repeated for only four years, the results of regression analysis for mean yield and maximum over 16 years for six locations (1, 2, 3, 8, 10, and 19) are summarized (Table 5). Regarding mean yield, the regression slopes for all six locations were close to 1 or greater than 1 (the $2^{\text {nd }}$ column in Table 5) and all were significantly except those for location 1 and 3. The slope measures the average annual soybean yield increase (equivalent to genetic improvement) for the last 16 years. For example, average annual soybean increase for location 19 was $2.18 \mathrm{bu} / \mathrm{ac}$ with the coefficient of determination of 0.57 . Annual soybean yield increases for locations 2,8 , and 10 were $1.50,1.64$, and $1.82 \mathrm{bu} / \mathrm{ac}$ with their corresponding coefficients of determination of $0.34,0.40$, and 0.36 . Regarding the maximum yield regression analysis over years, the slopes for location 1 or 3 was not significant. However, the slopes for locations 2, 8, 10, and 19 were greater than 1 , indicating the best performers could increase soybean yield more than 1 bu/ac annually.

The results of regression analysis for mean and max yield over 16 years for three maturity groups are summarized in Table 6. Both annul mean yield and max soybean yield significantly increased for maturity groups 0 and 1 but not for maturity group 2 (Table 6). On average, annual mean yield increases were $1.39 \mathrm{bu} / \mathrm{ac}$ and $1.52 \mathrm{bu} / \mathrm{ac}$ for maturity group 0 and 1 while the annual max yield increases were $1.45 \mathrm{bu} / \mathrm{ac}$ and $1.33 \mathrm{bu} / \mathrm{ac}$ for maturity groups 0 and 1 .

\section{Variance component analysis}


Since soybean varieties varied differently among years and locations within each year, using a linear model including genotype and GE interaction effects is not statistically appropriate to analyze the combined data set. In this study, we focused on analysis for each year data with a linear model that included effects of maturity group, variety, and location. Without losing our focus, only estimated proportional variance components for each of 16 years are summarized in Figure 9. The results showed environmental effects locations contributed the majority to the total variation for within each year, ranging from $39.0 \%$ (2007) to $95.5 \%$ (2005), indicating that environmental conditions among different locations within each year played a dominant role on soybean production in eastern South Dakota while maturity effects or genotypic effects on soybean yield were trivial compared to location effects.

\section{Discussion}

Annual crop performance trials are an essential step in crop breeding and production (Yan 2014). Many methods have been proposed for multi-environment data analysis to target GE interactions and yield stability (Zhang et al. 2012; Wu et al. 2012; Nurminiemi and Rognli 1996; Gray 1982; Lin et al. 1986; Fan et al. 2007). Exploring historical (multi-year) crop trial data could yield more information or help determine factors associated with crop production. However, the efforts to evaluate historical crop trial data could be statistically challenging, especially for longterm crop trial data with the use of the commonly used methods for yield stability or GE interactions due to highly unbalanced data structure (Mackay et al. 2011).

In this study, datasets including 16 years of South Dakota soybean yield trials were investigated. During our data processing, we observed several significant issues associated with these multi-year crop trial data: (1) most varieties in trials were repeated two or three years among years; (2) check lines were different from year to year; and (3) coding systems for brand and variety names were inconsistent among years. With these issues, we focused on three types of data analyses: (1) yield distribution across years, locations, and maturity groups using descriptive statistical methods; (2) associations between mean yield and maximum yield and testing years for each location and for each maturity groups using linear regression method; and (3) impact of environmental conditions from different locations within each year with linear mixed model approaches. Our results showed that yield distribution patterns varied among years, locations, and maturity groups. Overall, mean yield and maximum yield increased by 24 bu/ac (56\%) and 22 bu/ac (35\%) from 2001 to 2016. Twenty-three varieties from maturity groups 1 and 2 yielded more than $80 \mathrm{bu} / \mathrm{ac}$ in Brookings and Beresford in 2016. Regression analysis also showed annual yield increase was significant and thus was consistent with the trends of mean yield and maximum yield performance over these 16 years. We can consider that such overall annul increase in soybean was the result of long-term breeding efforts (Mackay et al. 2011; de la Vega et al. 2007). A recent study also showed similar patterns for six crops including winter wheat, winter barley, and spring barley 
in UK (Mackay et al. 2011). Within each year, the environmental conditions were a major factor to impact soybean production.

From this study, we also have had the following considerations to improve analysis and utilization of long-term yield trial data. The considerations include the same naming/coding systems for seed variety and brand, the same types traits like agronomy and quality traits, and the same genotypes used as check lines among years. Consistent naming systems could save a significant amount of time for statisticians for data processing. Consistent trait measurements could provide more information to determine patterns associated with crop production. Consistent use of the same check lines could help data analysis with linear mixed model approaches for the combined data or check-based yield stability determination (Wu et al. 2014).

Soybean production is a very complicated process, impacted by many factors including environmental conditions, genotypes, plant phenotypes, population sizes, and their potential interaction effects. In this study, we only applied three types of statistical data analyses to explore these historical soybean yield trial data and we found the results were consistent among each other. The results, which showed the genetic improvement pattern for soybean yield improvement in South Dakota over last 16 years, were our initial step for the data process. In our data analysis, we found that both mean and maximum yield were much lower in some years and locations. At this point, we were not clear which factors caused low yield in these environments (years or locations) without much other information. It might be due to drought or early frost in some locations or season. A recent study showed that nonlinear heat effects on African maize were detected by historical yield trials (Lobell et al. 2011). Therefore, it will be interesting to determine such factors including climate condition, which could cause significant yield production in South Dakota.

\section{References}

Crossa J, Gauch HG, Zobel RW (1990) Additive Main Effects and Multiplicative Interaction Analysis of Two International Maize Cultivar Trials. Crop Science 30 (3):493-500

de Figueiredo UJ, Nunes JAR, Parrella RAD, Souza ED, da Silva AR, Emygdio BM, Machado JRA, Tardin FD (2015) Adaptability and stability of genotypes of sweet sorghum by GGEBiplot and Toler methods. Genet Mol Res 14 (3):11211-11221. doi:10.4238/2015.September.22.15

de la Vega AJ, DeLacy IH, Chapman SC (2007) Progress over 20 years of sunflower breeding in central Argentina. Field Crop Res 100 (1):61-72. doi:10.1016/j.fcr.2006.05.012

Eberhart SA, Russell WA (1966) Stability parameters for comparing verirties. Crop Science 6:36-40

Fan XM, Kang MS, Chen HM, Zhang YD, Tan J, Xu CX (2007) Yield stability of maize hybrids evaluated in multi-environment trials in Yunnan, China. Agron J 99 (1):220-228

Finlay KW, Wilkinson GN (1963) The analysis of adaptation in a plant-breeding programme. Aust J Agric Res 14:742-752

Francis TR, Kannenberg LW (1978) Yield stability studies in short season maize. I. A descriptive method for grouping genotypes. Can J Plant Sci 58:1029-1034

Gray E (1982) Genotype $\times$ environment interactions and stability analysis for forage yield of orchardgrass clones. Crop Science 22:19-23

Kang MS, Miller JD (1984) Genotype $\times$ environment interactions for cane and sugar yield and their implications in sugar breeding. Crop Science 24:435-440 
Lin CS, Binns MR, Lefkovitch PL (1986) Stability analysis: where do we stand? Crop Science 26:894-899

Lobell DB, Banziger M, Magorokosho C, Vivek B (2011) Nonlinear heat effects on African maize as evidenced by historical yield trials. Nat Clim Change 1 (1):42-45. doi:10.1038/Nclimate1043

Mackay I, Horwell A, Garner J, White J, McKee J, Philpott H (2011) Reanalyses of the historical series of UK variety trials to quantify the contributions of genetic and environmental factors to trends and variability in yield over time. Theor Appl Genet 122 (1):225-238. doi:10.1007/s00122-010-1438-y

Nurminiemi M, Rognli OA (1996) Regression analysis of yield stability is strongly affected by companion test varieties and locations - Examples from a study of Nordic barley lines. Theor Appl Genet 93 (3):468-476. doi:Doi 10.1007/Bf00223192

Patterson HD, Thompson R (1971) Recovery of inter-block information when block size are unequal. Biometrika 58:545-554

R Core Team (2017) R: A language and environment for statistical computing. R foundation for statistical computing. Vienna, Austria

Rao CR (1971) Estimation of variance and covariance components MINQUE theory. . Journal of Multivariate Analysis 1:257-275

Wu J (2014) minque: An R package fir linear mixed model analyses. 1.1 edn., http://cran.r-project.org/

Wu J, Glover K, Berzonsky W Statistical tests for stability analysis with resampling techniques. In: Song W (ed) 24th Conference on Applied Statistics in Agriculture, Manhanttan, KS., 2012. pp 88-108

Wu J, Glover K, Mueller N Check based stability analysis method and its application to winter wheat variety trials. In: Song W (ed) 26th Annual Conference on Applied Statistics in Agriculture, Manhattan, KS, 2014. New Praire Press, pp 102-114

Yan W (2014) Crop Variety Trials: Data Management and Analysis. Wiley-Blackwell, New York, NY

Yan WK (2001) GGEbiplot - A windows application for graphical analysis of multienvironment trial data and other types of two-way data. Agron J 93 (5):1111-1118

Zhang J, Chen XF, Liu WG, Yang WY (2012) Stability analysis of yield and quality of Alisma orientalis (Sam.) Juzep by additive main effects and multiplicative interaction model. Res Crop 13 (1):338-345

Zhu J (1989) Estimation of genetic variance components in the general mixed model. Dissertation, North Carolina State,

Zhu J, Xu F, Lai MG (1993) Analysis methods for unbalanced data from regional trials of crop variety, analysis for single trait. Journal of Zhejiang Agricultural University 19:7-13 


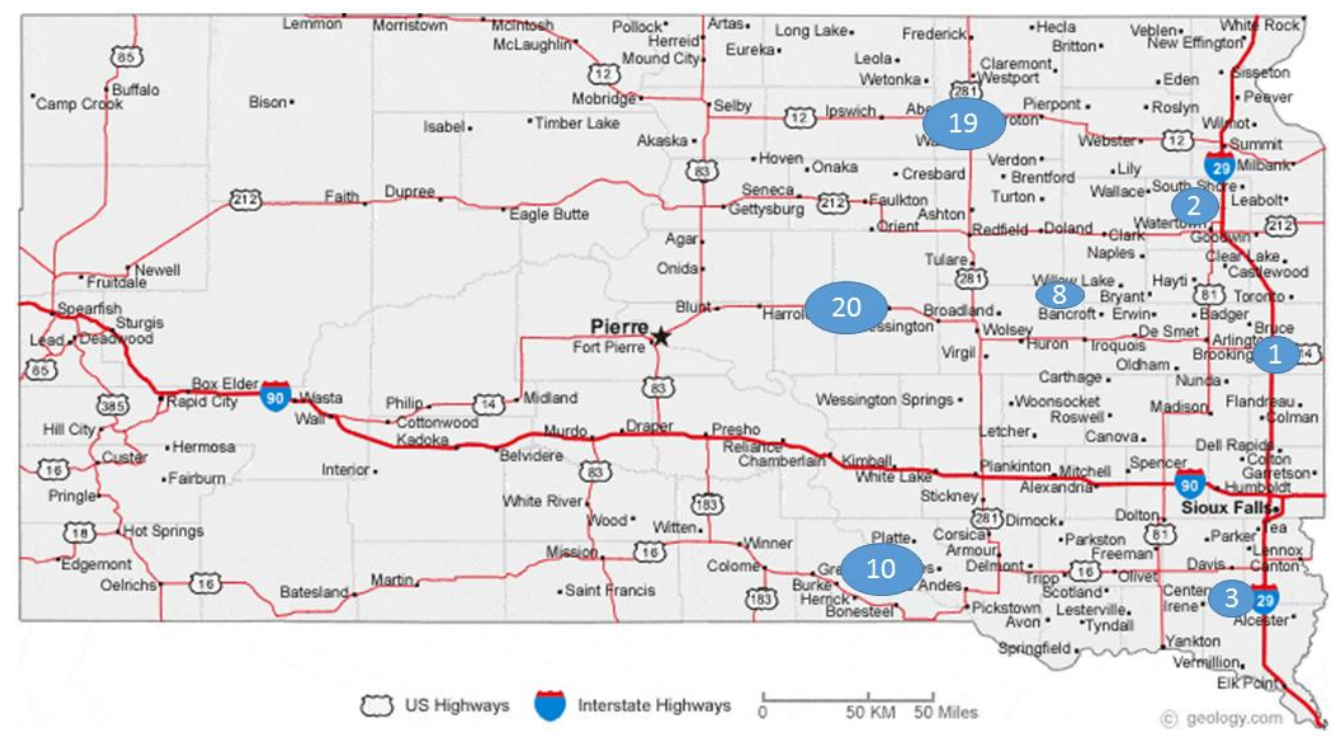

Figure 1. Seven soybean yield trial locations in Eastern South Dakota ( $1=$ Brookings; $2=$ South Shore; $3=$ Beresford; 8=Bancroft; 10=Geddes; 19=Aberdeen; and 20=Miller. 3 and 19 are located at maturity zone $0 ; 1,8$, and 20 are located at maturity zone 1 ; and 3 and 10 are located at maturity zone 2). 


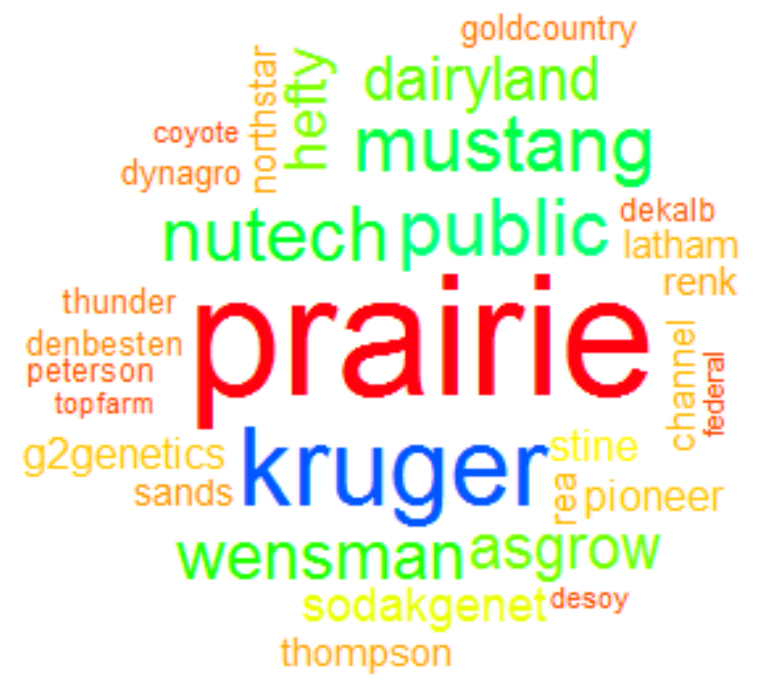

Figure 2. Most grown seed brands over 16 years (A larger font size represents more popular than a smaller font size. For example, seed brand Prairie was more popular than Dairyland. The $r$ package wordcloud was used to generate this figure). 


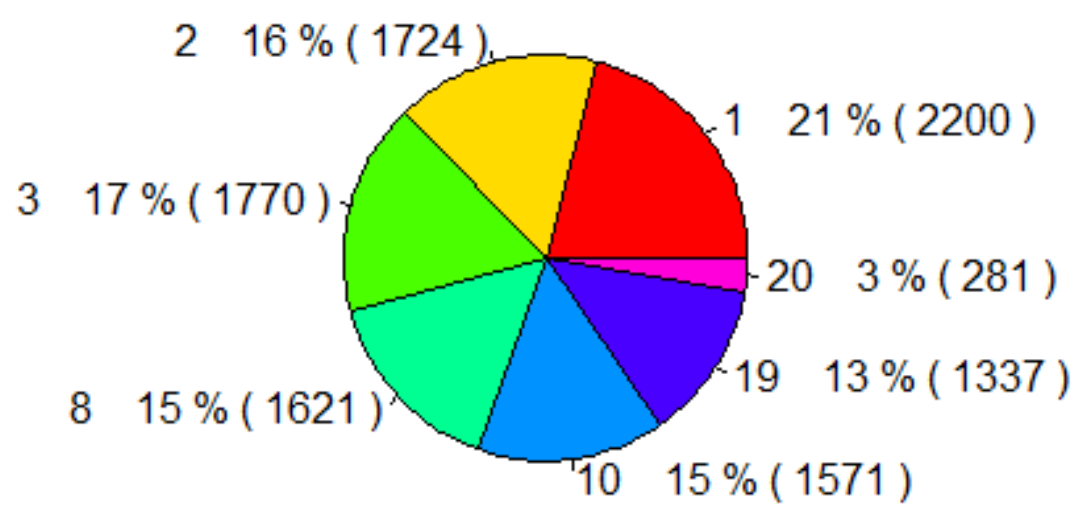

Figure 3. Soybean entry frequencies among seven locations ( $1=$ Brookings $; 2=$ South Shore; $3=$ Beresford; 8=Bancroft; 10=Geddes; 19=Aberdeen; and 20=Miller) 


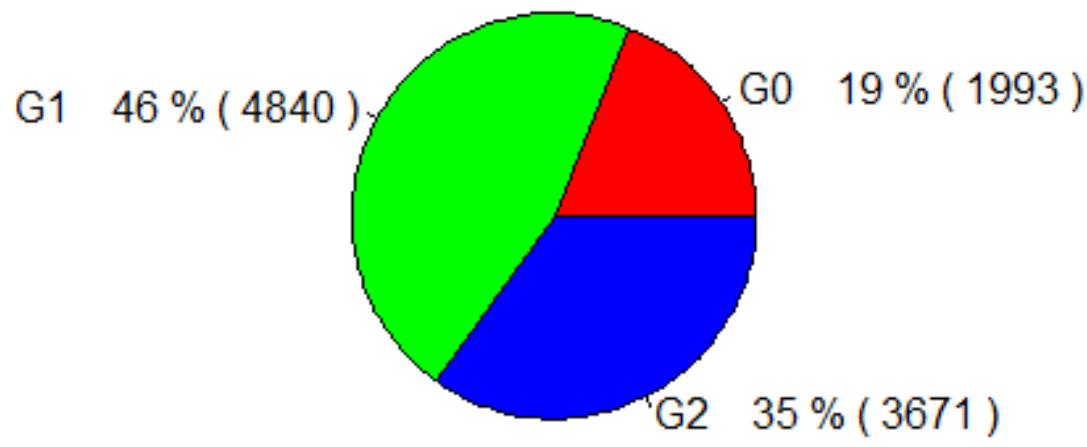

Figure 4. Soybean entry frequencies among seven locations $(\mathrm{G} 0=$ maturity group $1 ; \mathrm{G} 1=$ maturity group 1; and G2=maturity group 2). 


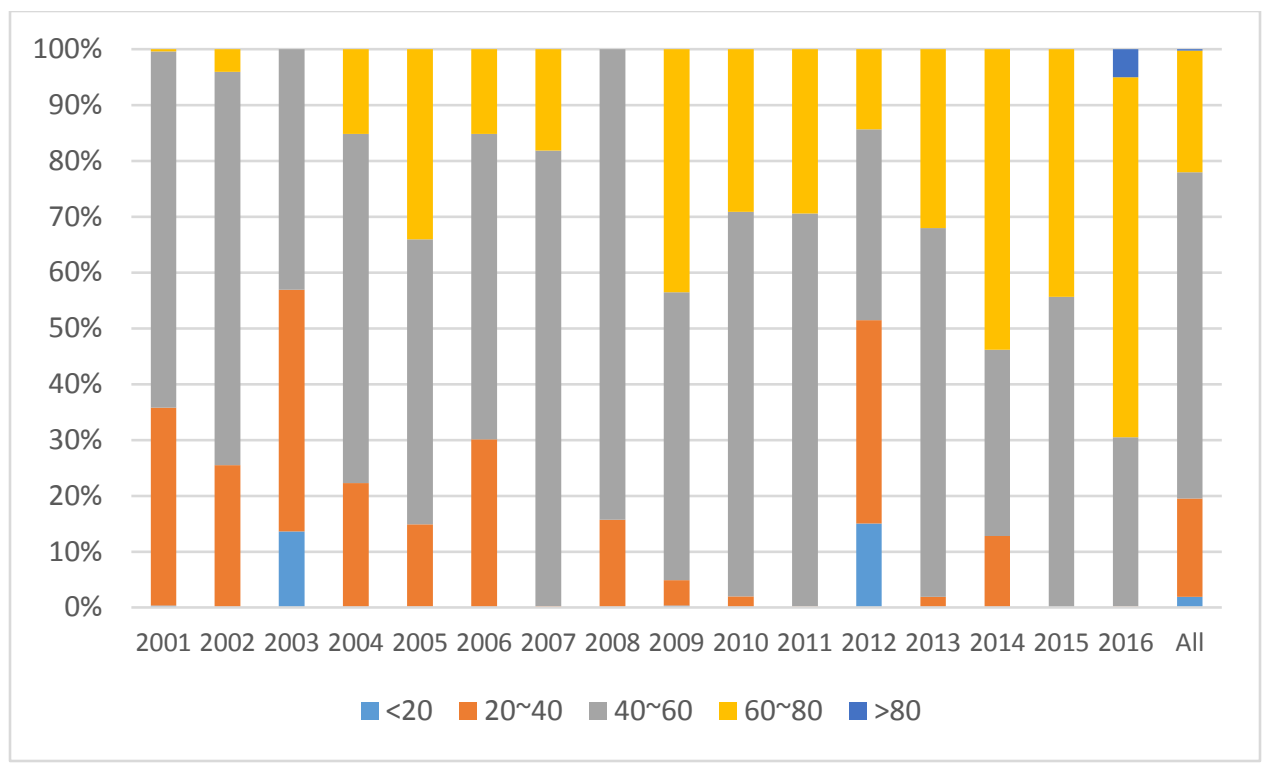

Figure 5. Soybean yield distribution for each of 16 trial years. 


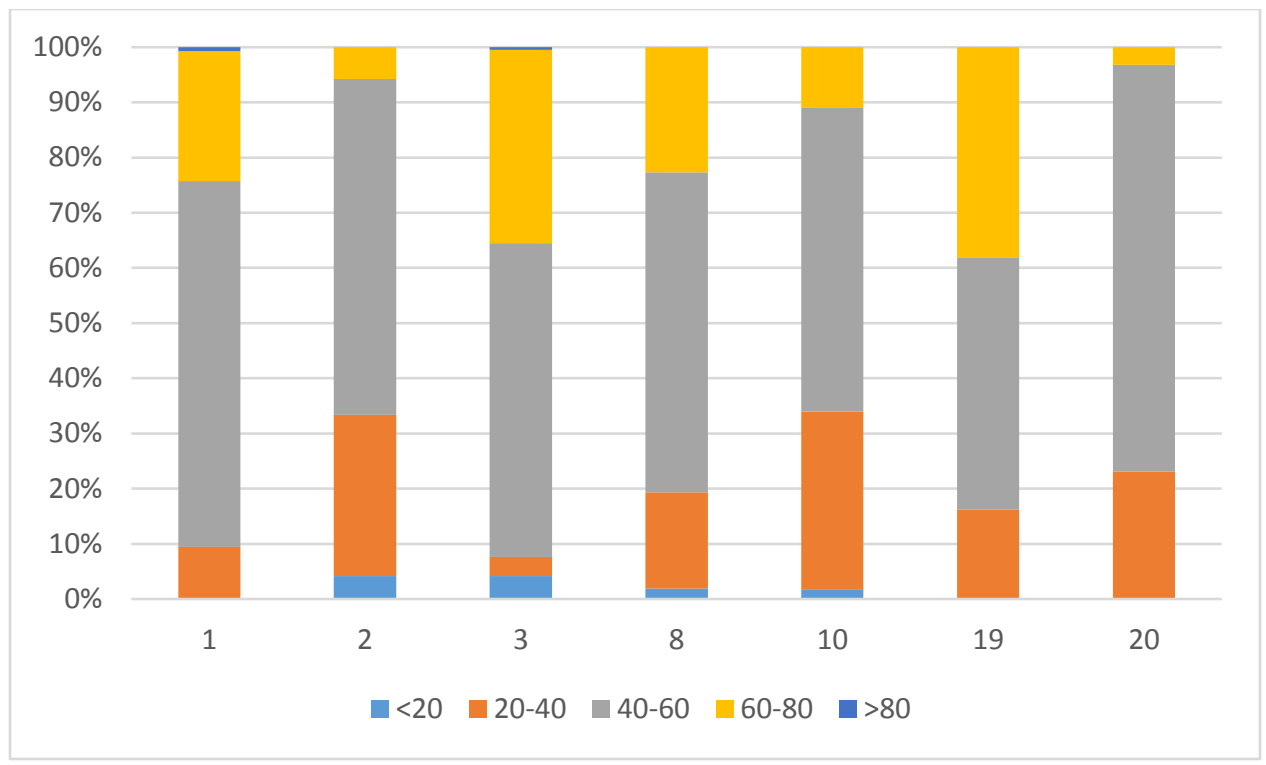

Figure 6. Soybean yield distribution for each of seven locations. 


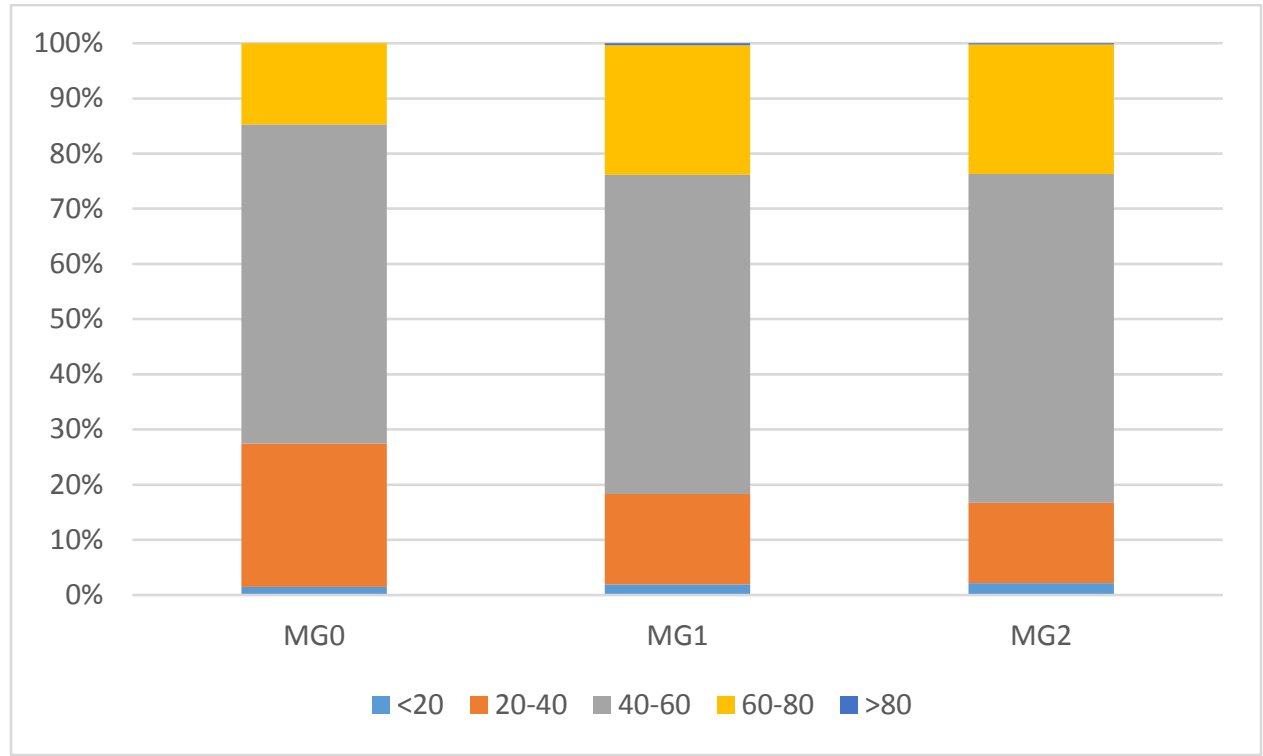

Figure 7. Soybean yield distribution for each of three maturity groups ( $\mathrm{MG}=$ maturity group). 


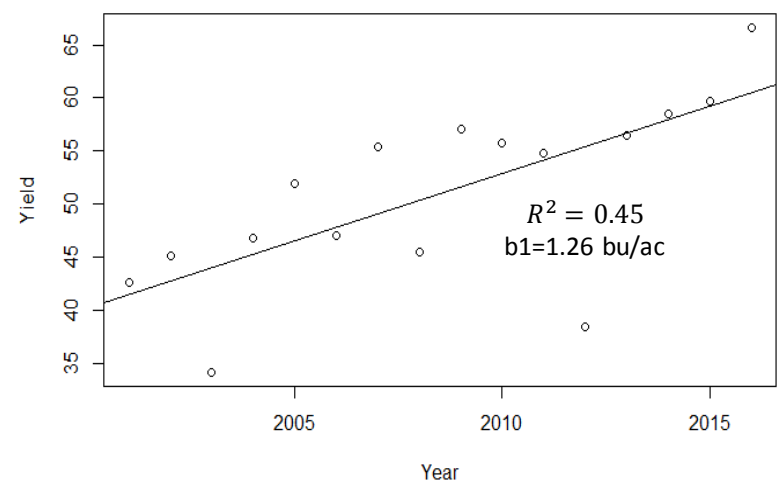

Mean yield vs year

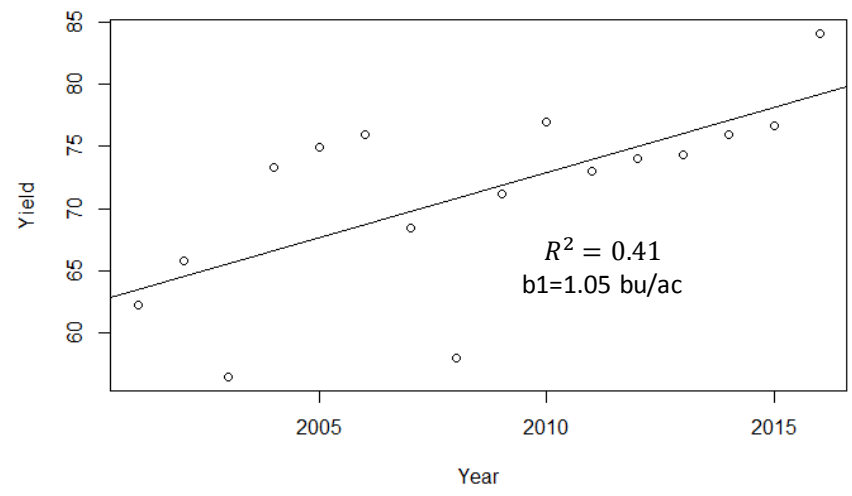

Maximum yield vs year

Figure 8. Linear regression of mean and maximum yields over trial years (2001-2016). 


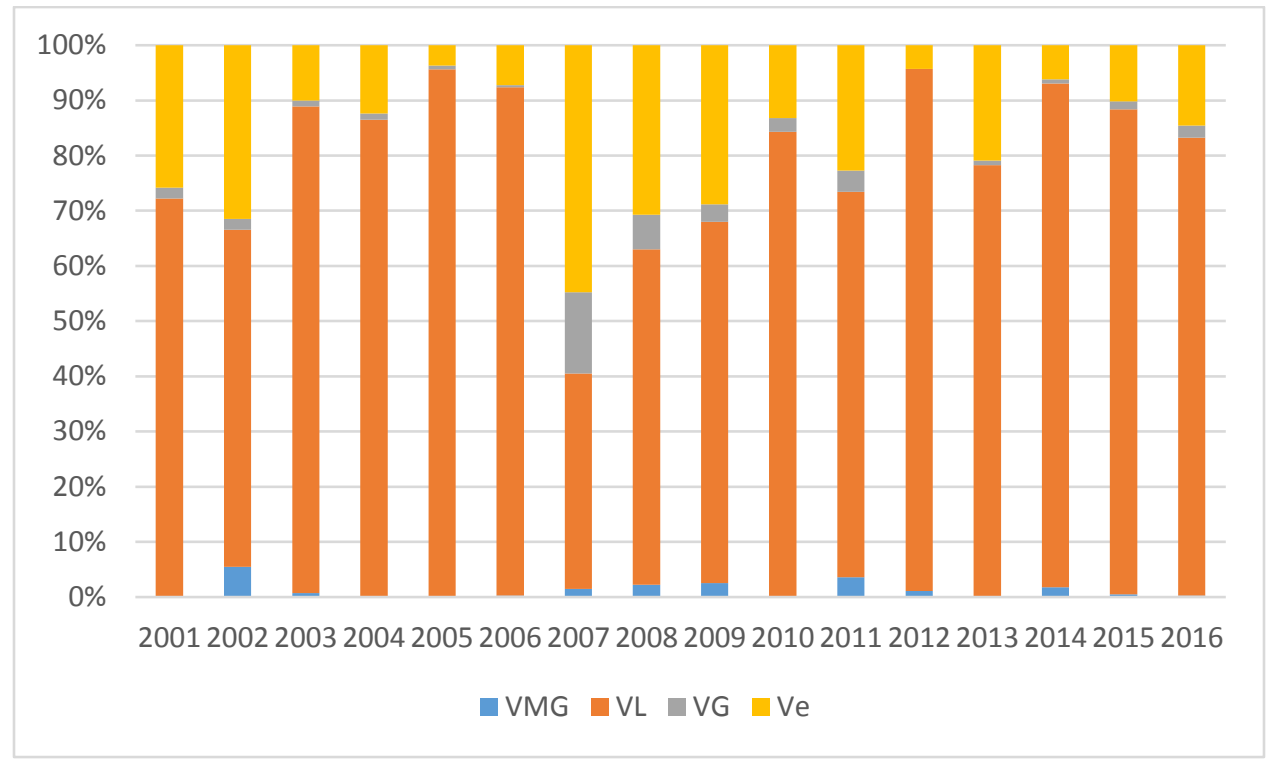

Figure 9. Contributions to the total variation for soybean yield from maturity group (VMG), location (VL), variety (VG), and residual (Ve) for each of 16 trial years. 
Table 1. Numbers of entries grown in each location and total entries, varieties, and seed brands for each year.

\begin{tabular}{rrrrrrrrrrr}
\hline \multicolumn{10}{c}{ Entries for each location } \\
\hline Year & 1 & 2 & 3 & 8 & 10 & 19 & 20 & Entries & Varieties & Brands \\
\hline 2001 & 246 & 148 & 216 & 122 & 195 & 0 & 0 & 927 & 416 & 39 \\
2002 & 242 & 152 & 184 & 153 & 160 & 0 & 0 & 891 & 393 & 39 \\
2003 & 194 & 130 & 148 & 124 & 110 & 108 & 0 & 814 & 321 & 33 \\
2004 & 193 & 162 & 144 & 0 & 121 & 144 & 0 & 764 & 344 & 33 \\
2005 & 157 & 132 & 125 & 133 & 116 & 124 & 0 & 787 & 294 & 27 \\
2006 & 143 & 111 & 132 & 127 & 123 & 108 & 0 & 744 & 266 & 29 \\
2007 & 139 & 107 & 111 & 131 & 101 & 100 & 0 & 789 & 239 & 22 \\
2008 & 135 & 96 & 113 & 122 & 99 & 89 & 0 & 654 & 239 & 23 \\
2009 & 137 & 87 & 103 & 112 & 88 & 86 & 0 & 613 & 234 & 19 \\
2010 & 101 & 71 & 76 & 81 & 60 & 71 & 0 & 460 & 189 & 16 \\
2011 & 70 & 97 & 79 & 97 & 70 & 97 & 0 & 510 & 209 & 17 \\
2012 & 104 & 91 & 93 & 100 & 93 & 90 & 0 & 571 & 197 & 16 \\
2013 & 83 & 88 & 61 & 75 & 61 & 87 & 63 & 518 & 166 & 18 \\
2014 & 82 & 79 & 70 & 74 & 67 & 72 & 65 & 509 & 175 & 24 \\
2015 & 104 & 97 & 67 & 95 & 62 & 86 & 86 & 597 & 191 & 22 \\
2016 & 70 & 76 & 48 & 75 & 45 & 75 & 67 & 456 & 151 & 19 \\
\hline
\end{tabular}


Table 2. Mean, minimum and maximum yield for each of 16 years.

\begin{tabular}{rrrrrrrr}
\hline Year & Mean & Minimum & Maximum & Year & Mean & Minimum & Maximum \\
\hline 2001 & 42.63 & 10.27 & 62.20 & 2009 & 57.08 & 16.07 & 71.17 \\
2002 & 45.23 & 25.47 & 65.80 & 2010 & 55.78 & 36.00 & 77.00 \\
2003 & 34.25 & 11.70 & 56.50 & 2011 & 54.82 & 39.00 & 73.00 \\
2004 & 46.88 & 22.33 & 73.30 & 2012 & 38.49 & 7.00 & 74.00 \\
2005 & 52.00 & 19.60 & 74.93 & 2013 & 56.43 & 35.00 & 74.30 \\
2006 & 47.06 & 21.27 & 75.93 & 2014 & 58.50 & 30.73 & 75.98 \\
2007 & 55.39 & 35.73 & 68.43 & 2015 & 59.75 & 40.36 & 76.68 \\
2008 & 45.57 & 31.33 & 57.97 & 2016 & 66.64 & 39.05 & 84.08 \\
\hline
\end{tabular}

Table 3. Mean, minimum and maximum yield for each of 16 years each of seven locations.

\begin{tabular}{rrrrrrrr}
\hline Location $^{\dagger}$ & Mean & Minimum & Maximum & Location & Mean & Minimum & Maximum \\
\hline 1 & 51.98 & 24.07 & 83.24 & 10 & 44.42 & 11.00 & 78.83 \\
2 & 43.60 & 11.80 & 69.73 & 19 & 53.24 & 24.17 & 75.51 \\
3 & 54.43 & 7.00 & 84.08 & 20 & 50.68 & 30.73 & 66.32 \\
8 & 50.59 & 10.27 & 79.31 & & & & \\
\hline
\end{tabular}

$\square$ : 1=Brookings, 2=South Shore, 3=Beresford, 8=Bancroft, 10=Geddes, 19=Aberdeen, and $20=$ Miller.

Table 4. Mean, minimum, and maximum yield for each of three maturity groups (MGs)

\begin{tabular}{llll}
\hline MG & Mean & Minimum & Maximum \\
\hline 0 & 47.11 & 11.80 & 73.29 \\
1 & 50.35 & 10.27 & 83.24 \\
2 & 50.52 & 7.00 & 84.08 \\
\hline
\end{tabular}


Table 5. Regression analysis for mean yield and maximum yield on trial years for six locations.

\begin{tabular}{lllllll}
\hline & \multicolumn{3}{l|}{ Mean yield } & \multicolumn{3}{c}{ Maximum yield } \\
\hline Location $^{\dagger}$ & $\mathrm{b}_{1}{ }^{*}$ & $\mathrm{R}^{2}$ & $\mathrm{P}$ & $\mathrm{b}_{1}$ & $\mathrm{R}^{2}$ & $\mathrm{P}$ \\
\hline 1 & 0.97 & 0.15 & 0.08 & 0.84 & 0.10 & 0.12 \\
2 & 1.50 & 0.34 & 0.01 & 1.30 & 0.23 & 0.03 \\
3 & 0.99 & 0.04 & 0.22 & 0.76 & 0.01 & 0.32 \\
8 & 1.64 & 0.40 & 0.01 & 1.41 & 0.35 & 0.01 \\
10 & 1.82 & 0.36 & 0.01 & 1.75 & 0.34 & 0.01 \\
19 & 2.18 & 0.57 & 0.00 & 1.87 & 0.51 & 0.00 \\
\hline
\end{tabular}

${ }^{\dagger}$ : 1=Brookings, 2=South Shore, 3=Beresford, 8=Bancroft, 10=Geddes, 19=Aberdeen, and $20=$ Miller.

$\ddagger \mathrm{b}_{1}=$ slope estimate, $\mathrm{R}^{2}=$ coefficient of determination; and $\mathrm{P}=$ probability level for slope $\mathrm{b}_{1}$.

Table 7. Regression analysis for mean yield and maximum yield on trial years for three maturity groups (MGs).

\begin{tabular}{llllllll}
\hline & \multicolumn{3}{c|}{ Mean yield } & \multicolumn{3}{c}{ Maximum yield } \\
\hline MG & $\mathrm{b}_{1}{ }^{*}$ & $\mathrm{R}^{2}$ & $\mathrm{P}$ & $\mathrm{b}_{1}$ & $\mathrm{R}^{2}$ & $\mathrm{P}$ \\
\hline 0 & 1.39 & 0.59 & 0.00 & 1.45 & 0.65 & 0.00 \\
1 & 1.53 & 0.58 & 0.00 & 1.32 & 0.60 & 0.00 \\
2 & 0.87 & 0.12 & 0.11 & 0.50 & 0.01 & 0.29 \\
\hline
\end{tabular}

$\overline{:} \mathrm{b}_{1}=$ slope estimate, $\mathrm{R}^{2}=$ coefficient of determination; and $\mathrm{P}=$ probability level for slope $\mathrm{b}_{1}$. 